\title{
Yeralt Madenciliğinde Risk ve Kadercilik Algılarının İş Güvenliği Algısı Üzerindeki Etkisi
}

\author{
The Influence of Perceived Risk and Fatalism \\ on Job Security Perception in Underground Mining
}

Öznur YAVAN

\begin{abstract}
ÖZET
Ekonomik, psikolojik ve sosyolojik açılardan oldukça önemli sonuçlar doğuran iş sağlığı ve güvenliği konusu çalışma hayatı kadar eskidir. Tehlikeli ve riskli endüstrilerde faaliyet gösteren çalışanların iş sağlığı ve güvenliği algıları güvenlik performansı kapsamında örgütlerin sürdürülebilirliğini etkileyen en güçlü unsurlardan biri olmaktadır. Bu çalışmanın amacı yeraltı madenciliğinde yaşanan kaza ve yaralanmalar sonucu oluşan risk algısı ve kadercilik boyutunun iş sağlığı ve güvenliği algısı üzerinde yarattığı etkileri ortaya koymaktır. Faktör analizleri sonucu risk algısı içsel ve dişsal risk olarak iki boyuta ayrılmıştır. İçsel risk algısı ile kadercilik inancının iş güvenliği algısı üzerinde istatistiksel olarak pozitif yönde anlamlı etkisi olduğu, dışsal risk algısının iş güvenliği algısı üzerinde istatistiksel olarak anlamlı bir etkisinin olmadığı sonucuna ulaşılmıştır. İlişkiler SPSS 19 paket programı ile korelasyon ve regresyon analizleri yapılarak gerçekleştirilmiştir.
\end{abstract}

Anahtar Kelimeler: Kaza, Risk, Kadercilik, İş Sağlığı ve Güvenliği

\section{ABSTRACT}

Occupational health and safety issues, which have very important consequences from economic, psychological and sociological aspects, are as old as working life. Occupational health and safety perceptions of employees operating in hazardous and risky industries are among the most powerful elements affecting the sustainability of organizations within the context of safety performance. The aim of this study is to reveal the effects of the risk perception that result from accidents and injuries and fatalism on the perception of occupational health and safety in underground mining. As a result of the factor analyzes, the risk perception is divided into two dimensions as internal and external risk. Internal risk perception and fatalism have a statistically significant positive effect on the job security perception and the external risk perception does not have a statistically significant effect on the job security perception. Relations were performed by correlations and regression analyzes with SPSS 19 packet program.

Key Words: Accident, Risk, Fatalism, Occupational Health and Safety

Yrd. Doç. Dr. Öznur YAVAN - Bülent Ecevit Üniversitesi, İktisadi ve İdari Bilimler Fakültesi, Zonguldak, Türkiye Assist. Prof. Oznur YAVAN - Bulent Ecevit University, Faculty of Economic \& Administrative Sciences, Zonguldak, Turkey 


\section{GİRIŞ}

Örgütler için iş sağllğı ve güvenliği her geçen gün daha da önemli hale gelmektedir. Sağlıklı bireyler, sağlıklı toplum ve gelişmişlik, iç içe büyüyen yapılardır. Ülkelerin gelişmişlik düzeyleri konusunda önemli belirleyicilerden biri iş sağlığı ve güvenliği uygulamalarına ayırdıkları maddi -manevi yatırımdır. İş sağlığı anlamında kastedilen sağlık, çalışanların sadece fiziksel sağlığı değil psikolojik ve sosyal anlamda da sağlığını kapsamaktadır. Özellikle riskli ve tehlikeli endüstri sektöründe çalışan bireylerin psikolojik ve sosyal anlamdaki sağlıkları, hem yaşanan kaza ve yaralanma boyutunda hem de ağır endüstri grubundaki örgütlerin performans ve verimlilikleri boyutunda etkilidir.

İşverenlerin iş güvenliğine verdikleri önem çalışanlar tarafından kendilerine verilen önem olarak algılanmakta psikolojik ve sosyal sağlıklarını olumlu şekilde etkilemektedir. İş sağlığı ve güvenliği konuları karşılıklı olarak birbirini güçlendiren unsurlardır. İş güvenliğine verilen önem, çalışanların daha az riskli davranışlar göstermelerine sebep olmaktadır. Benim başıma gelmez zihniyeti ve işi kısa yoldan yapma yaklaşımı güvenlik kültürünün yerleştiği örgütlerde gittikçe azalmaktadır. Böylece işgünü ve işgücü kayıplarında önemli bir düşüş görülmektedir. Örgüt kültüründe güçlü bir iş sağlı̆̆ı ve güvenliği algısı yerleşmişse örgütte işler ve işlerin yapilış şekilleri daha verimli olacaktır.

Yapılan birçok istatistiki çalışma özellikle Türkiye gibi gelişmekte olan ülkelerde iş kazaları ve bu kazalar sonucu yaşanan ölüm vakalarında ciddi artışlar olduğunu göstermektedir. Örgütler büyümeyi ve sürdürülebilirlik kazanmayı, ülkeler gelişmeyi hedefliyorsa, iş sağlığı ve güvenliği uygulamaları bu hedefleri istenen sonuçlara ulaştıran temel katalizörlerden biridir.

\section{ARAŞTIRMANIN KAVRAMSAL ÇERÇEVESİ}

İnsan, var olduğundan beri öncelikle yaşamak için gerekli ihtiyaçlarını karşılamak amacıyla çalışmak durumundadır. "Bir tehlike karşısında korunmayı ve tehlikenin gerçekleşmesi durumunda ise bundan kurtulma" (Demirbilek, 2005:4) olarak ifade edilen güvenlik de insanın karşılamak istediği önemli bir ihtiyaçtır. Bu ihtiyaç, insanın günlük yaşamının yanı sıra çalışma hayatında da mevcuttur. $\mathrm{Bu}$ noktadan hareketle, işçi sağlığı ve iş güvenliğine dair çalışmaların, çalışma hayatının tarihi ile aynı zamanda başladığı ve paralel ilerlediği öne sürülebilir (Uslu, 2002:1-4).

İvedi ve belirli ödüllerin (sağlı̆ı̆ı iyi olması) ya da cezaların (yaralanma ya da hastalıktan kaynaklanan acı ve ıst1rap) yokluğundan dolayı çalışanlar genellikle iş sağlığı ve güvenliği konusunda güçlü bir motivasyona sahip olma eğilimine girmezler. Ayrıca, iş sağlığı ve güvenliği eğitimlerinde sağlanan bilgiler kişisel deneyimlerle etkisizleştirilebi- lir. İşçiler, 'Bunu 20 yıldır bu şekilde yaptım ve hiç kaza geçirmedim' görüşünü savunabilir veya emniyet prosedürünü takip etmeyen diğer işçilerin davranışlarının belirgin bir olumsuz sonuç doğurmadığını gözlemleyebilir. Araştırmalar, çalışanların yaralanma veya hastalık doğurmayan güvensiz davranışlarını tekrar tekrar deneyimlemelerinin sistematik duyarsızlaşma ve hafifleyen korkuya yol açtığını doğrulamaktadır (Lingard, 2002:265).

Uluslararası Çalışma Örgütü’nün (ILO) verilerine göre dünyada, her 15 saniyede 160 iş kazası meydana gelmekte, her 15 saniyede bir işçi, iş kazası veya meslek hastalığı sonucunda ölmektedir. Dolayısıyla, her gün 6.300 kişi iş kazası veya meslek hastalığı sonucunda ölmektedir. Kötü iş sağlığı ve güvenliği uygulamalarının ekonomik maliyeti, her gün yaşanan 1 milyon iş kazası sonucu; her yıl dünya gayri safi hasılasının \%4’ü olduğu tahmin edilmektedir. Ülkemizde iş kazası rakamlarının yüksek olması ve meslek hastalıkları rakamlarının tam olarak ortaya konulması bu yönde yapılacak çalışmaların önemini ortaya koymaktadır (Ayan v.d., 2013:6)

2012 yılında yayımlanan İş Sağlığı ve Güvenliği Kanunu $\mathrm{m} 3 / \mathrm{g}$ 'de iş kazası "İşyerinde veya işin yürütümü nedeniyle meydana gelen, ölüme sebebiyet veren veya vücut bütünlüğünü ruhen ya da bedenen engelli hale getiren olay", meslek hastalığı m.3/l'de, "mesleki risklere maruziyet sonucu ortaya çıkan hastalık" olarak tanımlanmıştır. İş sağlığı ve Güvenliği Kanunu ile çalışanların ve işverenlerin sorumlulukları ve yükümlülükleri ortaya konulmuş ve koruyucu önlemlerin çalışan-işveren işbirliği ile birlikte alınması yaklaşımı temel prensip olarak kabul edilmiştir (Ayan v.d., 2013:7).

Tehlikeler her işyerinde mevcuttur fakat ne oldukları konusunda gerekli farkındalık düzeyi düşüktür. Bu tehlikeleri ve çalışanları yönetmek için elzem olan sistemler ve tehlikelere verilen tepkiler ise yetersiz veya uygunsuz olabilmektedir (Chapman, 2007:26-27). Çünkü güvenlik kültürünün soyut ve somut bileşenleri vardır. Somut faktörler kurallar ve prosedürler, sayısal veriler olmakla birlikte iş sağlığı ve güvenliği kültürünün yalnızca $\% 10$ 'unu karşılamaktadır. Buna karşın soyut faktörler ise yazılı olmayan kurallar, algılar ve inanışlar olup iş sağlığı ve güvenliği kültürünün \%90'ını karşılamaktadır (Aytaç, 2017:61).

Kazaların kişisel yaşanma düzeyi seyrektir ve birçok meslek hastalığı uzun bir gizlilik sürecine sahiptir. Dolayısıyla, iş sağlığı ve güvenliği konusundaki olumsuz sonuçların doğrudan kişisel tecrübesi nadirdir. Çalış̧anlar da genellikle gerçek olamayacak kadar iyimser bir inanışa sahiptirler 'benim başıma gelmeyecek' (Lingard, 2002:265-269).

Yapılan çalışmalar, işyeri yaralanmaları ve ölümle sonuçlanan kazaların \%85'inin kaçınılabilir olduğunu ve bu 
kazaların insan hatasından kaynaklandığını göstermektedir (Neville, 1998:8; Eastman, 1969:46-144). İş kazalarının sayısını azaltabilmek için öncelikle meydana gelmiş kazaların sistematik bir şekilde incelenmesi gerekmektedir. Bu inceleme, özellikle iş güvenliği çalışmalarının yönlendirilmesi açısından önem taşımaktadır (Tarhan vd., 2012:371). İş sağlığı ve güvenliği düzenlemelerinin amacı, kazaların meydana gelmesini önlemek ve önlenemeyen kazaların ciddiyetini azaltmaktır (Gruenspecht ve Lave, 1988:1523).

Kaza ve yaralanmalar sonrası oluşan risk algısı ile mesleki risk davranışı arasında önemli bir pozitif çağrışım bulunmaktadır. Çalışanların algıladığı yüksek risk, davranışlarının daha fazla risk içermesine sebep olmaktadır. Algılar, davranışları etkilemektedir. Genellikle farz edilen şudur; kazalar olmaktadır çünkü bireylerin risk algıları konusunda yanlış bir şeyler söz konusudur. Risk konusunda alınan yanlış hükümler, güvenli olmayan davranışlar ve beşer hataları kadar yersiz kararlar alınmasına sebep olmaktadır. Sonuç olarak, bir çalışan herhangi bir riske maruz kaldığında bir kaza gerçekleşmektedir. Çünkü risk algısı, gerçek riske dönüşmektedir (Yavan, 2013:50-51).

Kadercilik öğrenilmiş çaresizlik, işlevsizlik, dünya görüşü ile eş tutulmaktadır. Kadercilik kontrolün dışsal hali, önceden belirleme, yaşananların kayıtsız kabulü, yanıtların üstesinden gelmek şeklinde nitelendirilmektedir (Esparza, 2005:1-6). Bir örgütteki iş çevresinin tehlikeli yapısının kabulü ile kaza kaderciliği arasındaki bağ son zamanlarda yeniden onaylanmıştır. Kaza raporları üzerine yayınlanmış literatür, kaza oranlarının meslek tipi ile birlikte çeşitlendiğini göstermektedir. (Gyekye, 2003:533-535).

İnsan-çevre uyumunun düşük olması, strese ve artan kaza riski deneyimlerinin yükselmesine sebep olmaktadır. Mesleki bir kazanın algılanan riski ne kadar yüksek olursa, çalışanların kaderci yöneliminin o kadar fazla olacağı savunulmaktadır. Tersi durumda da kaderci yönelim, o kadar düşük olmaktadır. Yeraltı madenciliğinin riskli ve tehlikeli yapısı çaresizlik duygusu çağrıştırarak, madencilerin inkârcı, kaderci ve savunmasız tepkiler göstermesine yol açabilecek sindirici ve stresli çalışma çevreleri olmaktadır (Gyekye, 2003:533-535). Özellikle tehlikeli ve riskli endüstri gruplarında yöneticilerin güvenlik tutumlarını etkileyen unsurlar; bağ llık, katılım, kazaları önlemeye dair kadercilik, endişe ve risk bilinci olmaktadır (Rundmo ve Hale, 2003:571; Yavan, 2013:51-52).

İş kazaları kavramını tanımlarken bu kazaları ortaya çıkaran nedenler her ne kadar beklenmedik ve bir anda ortaya çıkan ve önemli can ve mal kayıplarına neden olan çok farklı etkenlerin sonucu olarak belirtilse de önceden tahmin edilmesi ve hatta önlenmesi çoğu zaman mümkün olan olaylar olarak da görülmelidir. Felaketlerin ve kazaların çoğunlukla kader olmadığı, eğer önceden gerekli ön- lemler alınabilirse bu felaketlerin önlenebileceği ya da en az hasarla atlatılabileceği bilimsel ve teknik olarak kanıtlanabilmiştir. Uzun vadede riskleri azaltıcı ve risklere karşı bilinç arttırıcı faaliyetler uygulanamaması hem çalışanlar hem de bölgede yaşayanlar için risk algısı ve değerlendirme kapasitesi oluşturulamamasına, daha kaderci bir yaklaşım izlenmesine ve bilinmeyene karşı her zaman büyük bir korku ve endişe taşınmasına neden olmaktadır (Özden, 2012:1-14).

Yaşanan kaza ve yaralanmalar sonucu oluşan risk algısı, kadercilik boyutu, iş sağlığı ve güvenliği boyutları arasında anlamlı ilişkiler bulunmaktadır. Çalışanların iş sağlığı ve güvenliği konusundaki algıları yaşanan kaza ve yaralanmalar sonucu oluşan risk algılarından ve kaderci yapilarından etkilenmektedir. Çalışmada bu ilişki ve etkileşimler incelenmektedir.

\section{ARAŞTIRMANIN AMPİRIKK ANALIZZI}

Çalışmanın bu kısmında araştırmanın amacı, hipotezleri, örneklem kütlesi, araştırmada kullanılan ölçekler hakkında bilgiler verilmektedir.

\section{A. Araştırmanın Amacı ve Hipotezleri}

$\mathrm{Bu}$ çalışmanın amacı tehlikeli ve riskli endüstrilerde yaşanan kazaların yarattığı risk algısı ve kaderci yaklaşımın, iş sağlığı ve güvenliği algısı üzerindeki etkilerini incelemektir. Bu kapsamda çalışmanın hipotezleri aşağıdaki gibidir:

$\mathrm{H}_{1}$ : Yeraltı madencilerinin yaşadıkları kazalar sonucu oluşan risk algıları iş güvenliği algıllarını etkilemektedir.

Hı: Yeraltı madencilerinin yaşadıkları kazalar sonucu oluşan dışsal risk algıları iş güvenliği algılarını etkilemektedir.

Hıb: Yeraltı madencilerinin yaşadıkları kazalar sonucu oluşan içsel risk algıları iş güvenliği algılarını etkilemektedir.

$\mathrm{H}_{2}$ : Yeraltı madencilerinin kadercilik inançları iş güvenliği algılarını etkilemektedir.

\section{B. Araştırmanın Örneklemi}

Madencilik sektöründe yeraltında çalışan 607 adet çalışana ulaşılmışırı. Örnekleme türü; TTK'na bağlı her bir müesseseden çalışan sayısına oranlanarak tabakalı örnekleme yoluyla iş güvenliği eğitimine alınan yeraltı madencilerinden oluşmaktadır. Anketler iş güvenliği eğitimi derslerinde, madencilerin yorgun olmadığı, zamanlarının bol olduğu derslik ortamında doldurulmuş ve bu uygulamanın periyodik olarak sürekliliği sağlanmıştır. Sınıf ortamında tüm soruların cevaplanabilmesi için yeterli zaman ve ortam 
yaratılmıştır. Verilerin gerçeğe yakın olmasına katkı sağlamak amacıyla süre kısıtlanmamış ve verilerin elde edilmesi Şubat-Temmuz (2012) ayları arası olmak üzere altı aylık bir süreci kapsamıştır. (Yavan, 2013:103).

\section{Araştırmanın Ölçekleri}

Madencilerin algıladıkları iş riskini ölçmek amacıyla, Morgan'ın (2007) sağlık sektörü çalışanları için kullanmış olduğu 10 soruluk iş riski ölçeği madencilik sektörüne uyarlanmıştır. Çalışmada ölçeğin Cronbach's Alpha değeri 0,829 olarak bulunmuştur. (Yavan, 2013:100). Madencilerinin güvenlik konusundaki kadercilik tutumlarını ortaya koymak amacıyla, Esparza'nın (2005) kullanmış olduğu ölçek madencilik sektörüne uyarlanmıştır. Çalışmada ölçeğin Cronbach's Alpha değeri 0,570 olarak belirlenmiştir. Çalışanların işyeri güvenliği konusundaki endişelerini ölçmek amacıyla McCaughey'in 2008 yılında Kanada'da yaptığı doktora tezi çalışması ölçeği kullanılmıştır. Çalışmada ölçeğin Cronbach’s Alpha değeri 0,836 çıkmıştır.

\section{VERİ ANALİZİ VE BULGULAR}

Ölçeklerin yapı geçerliliği için doğrulayıcı faktör analizi uygulanmıştır. Faktör analizinde özdeğerlerin 1'den büyük olması halinde faktörler oluşacak şekilde tasarlanmıştır. Veri setinin faktör analizine uygunluğunu test eden KaiserMeyer-Olkin (KMO) ve Bartlett Küresellik testleri aşağıdadır. İş güvenliği ölçeğine uygulanan faktör analizi sonucunda "İşism güvenli" sorusu düşük faktör yükünden dolayı güvenilirliği düşürdüğü tespit edilmiş ve ölçme aracından çıkarılarak ölçeğin güvenilirliği 0,870 'e yükseltilmiştir.

Tablo 1: KMO ve Bartlet Test Sonuçları

\begin{tabular}{lccc}
\hline & KMO & Bartlet's Test & Sig. \\
İs güvenliği &, 882 & $2126,969(45)$ &, 000 \\
Kaza riski &, 871 & $1988,277(45)$ &, 000 \\
Kadercilik &, 673 & $232,035(10)$ &, 000 \\
\hline
\end{tabular}

KMO ve Bartlet test sonuçları değişkenler arasında yüksek korelasyonun mevcut olduğunu, diğer bir ifadeyle veri setinin faktör analizi için uygun olduğunu göstermektedir.
Tablo 2: Kadercilik Ölçeğinin Geçerlilik ve Güvenilirlik Analizi Sonuçları

\begin{tabular}{|c|c|c|c|c|}
\hline & 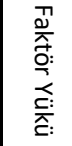 & 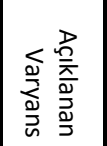 & 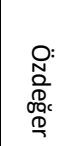 & 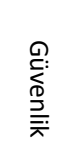 \\
\hline & & 36,898 & 1,845 & ,570, \\
\hline $\begin{array}{l}\text { İşyerimde güvenliği geliştirmek } \\
\text { için hiçbir şey yapamam. }\end{array}$ & 606 & & & \\
\hline $\begin{array}{l}\text { Sürekli güvenlik konusunda endi- } \\
\text { şelenseydim işlerimi yapamazdım. }\end{array}$ & ,522 & & & \\
\hline $\begin{array}{l}\text { İsimde risk almaktan uzak kalamı- } \\
\text { yorum. }\end{array}$ & ,654 & & & \\
\hline $\begin{array}{l}\text { Kazalar yaşanacaksa yaşanır, ne } \\
\text { yaptı̆ımın önemi yok. }\end{array}$ & ,608 & & & \\
\hline $\begin{array}{l}\text { Güvenlik unsurları biz işe başlayın- } \\
\text { caya kadar çalısıır, sonra diğer } \\
\text { şeyler (üretim, verimlilik, perfor- } \\
\text { mans vb.) öncelik alır. }\end{array}$ & ,639 & & & \\
\hline
\end{tabular}

Faktör analizi sonucunda yaşanan kaza ve yaralanmalar sonucu oluşan kadercilik yaklaşımı ölçeğinde yer alan 5 maddenin tek boyut altında gruplandığı görülmüştür. Kadercilik yaklaşımı ölçeği ile ilgili faktörde "İşyerimde güvenliği geliştirmek için hiçbir şey yapamam $(0,606)$ ”, "Sürekli güvenlik konusunda endişelenseydim işlerimi yapamazdım $(0,522)$ ", "İşimde risk almaktan uzak kalamıyorum $(0,654)$ ", "Kazalar yaşanacaksa yaşanır, ne yaptığımın önemi yok $(0,608)$ ", "Güvenlik unsurları biz işe başlayıncaya kadar çalışır, sonra diğer şeyler (üretim, verimlilik, performans vb.) öncelik alır $(0,639)$ " yükleriyle kadercilik yaklaşımına ilişkin maddeler bulunmaktadır. Boyutun açıklanan varyansı 36,898, özdeğeri 1,845, güvenilirliği 0,750 olarak belirlenmiştir. 
Tablo 3: Risk Ölçeğinin Geçerlilik ve Güvenilirlik Analizi Sonuçları

\begin{tabular}{|c|c|c|c|c|}
\hline & 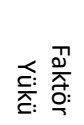 & 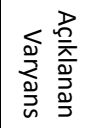 & $\begin{array}{c}\text { O: } \\
\text { O } \\
\text { D } \\
\text { occ } \\
\text { D. }\end{array}$ & 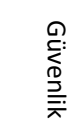 \\
\hline & & $\begin{array}{l}41,47 \\
7\end{array}$ & 4,148 & 829 \\
\hline $\begin{array}{l}\text { Kayma, dengenizi kaybedip düş- } \\
\text { me ve yaralanma }\end{array}$ & 096 & & & \\
\hline $\begin{array}{l}\text { Göçük, taş veya kömür düşmesi } \\
\text { sonucu yaralanma }\end{array}$ & 188 & & & \\
\hline $\begin{array}{l}\text { El aletleri kullanımından dolayı } \\
\text { yaralanma }\end{array}$ & ,222 & & & \\
\hline $\begin{array}{l}\text { Elle veya mekanik taşımadan } \\
\text { kaynaklanan kazalar }\end{array}$ & ,212 & & & \\
\hline Gaz veya toz patlaması & 795 & & & \\
\hline Yangın veya kendiliğinden yanma & ,756 & & & \\
\hline Gazdan boğulma ve zehirlenme & 824 & & & \\
\hline Su basması & ,634 & & & \\
\hline Elektrikten kaynaklanan kazalar & ,706 & & & \\
\hline $\begin{array}{l}\text { Çalışırken ne sıklıkta aşırı zorlan- } \\
\text { dığınız durumlar oluyor }\end{array}$ & 172 & & & \\
\hline
\end{tabular}

Faktör analizi sonucunda yaşanan kaza ve yaralanmalar sonucu oluşan risk algısı ölçeğinde yer alan 10 maddenin 2 boyut altında gruplandığ 1 görülmüştür. İlk boyut işyeri çevresinin yapısından kaynaklanan kaza ve yaralanmalara sebep olan dişsal risk olarak isimlendirilebilir. İkinci boyut çalışanın kendisinden kaynaklanan risk unsurları olarak içsel risk olarak isimlendirilebilir.

Dışsal risk algısı ile ilgili faktörde "Gaz veya toz patlaması (0,795)", "Yangın veya kendiliğinden yanma $(0,756)$ ", "Gazdan boğulma ve zehirlenme $(0,824)$ ", "Su basması (0,634)", "Elektrikten kaynaklanan kazalar $(0,706)$ " gibi dışsal risk algısına ilişkin maddeler bir araya gelmiştir. İçsel risk algısı ile ilgili faktörde "Kayma, dengenizi kaybedip düşme ve yaralanma $(0,096)$ ”, "Göçük, taş veya kömür düşmesi sonucu yaralanma $(0,188)$ ”, "El aletleri kullanımından dolayı yaralanma $(0,222)$ ", "Elle veya mekanik taşımadan kaynaklanan kazalar $(0,212)$ ”, "Çalışırken ne sıklıkta aşırı zorlandığınız durumlar oluyor $(0,172)$ " gibi içsel risk algısına ilişkin maddeler bir araya gelmiştir. Boyutun açıllanan varyansı 41,477, özdeğeri 4,148, güvenilirliği 0,829 olarak belirlenmiştir.
Tablo 4: İș Güvenliği Ölçeğinin Geçerlilik ve Güvenilirlik Analizi Sonuçları

\begin{tabular}{|c|c|c|c|c|}
\hline & 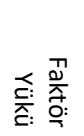 & 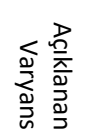 & 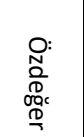 & 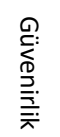 \\
\hline & & 49,332 & 4,440 & ,836 \\
\hline İşim tehlikeli & 667 & & & \\
\hline İş̧im zararlı & 654 & & & \\
\hline İşim riskli & ,671 & & & \\
\hline İşimde kolayca yaralanılabilir & 663 & & & \\
\hline İşim güvensiz & 624 & & & \\
\hline İşim korkutucu & ,704 & & & \\
\hline İşim sağlıksız & ,754 & & & \\
\hline İşimde ölüm olasılığı yüksek & ,780 & & & \\
\hline $\begin{array}{l}\text { İşimde sağıı̆ımın bozulma olasılı̆̆ı } \\
\text { yüksek }\end{array}$ & ,784 & & & \\
\hline
\end{tabular}

İş güvenliği ölçeğinde olumsuz anlam taşıyan “işim güvenli” sorusu analizden çıkarıldıktan sonra tekrarlanan faktör analiz sonuçları tabloda yer almaktadır. İş güvenliği algısı ölçeği le ilgili fatörde "İşim tehlikeli $(0,660)$ ", "İşim zararlı $(0,651)$ ", "İşim riskli $(0,664)$ ", "İşimde kolayca yaralanılabilir $(0,662)$ ”, "İşim güvensiz $(0,630)$ ”, "İşim korkutucu $(0,707)$ ”, “İşim sağlıksız $(0,758)$ ”, “İşimde ölüm olasılığı yüksek $(0,781)$ ", "İşimde sağlığımın bozulma olasılığı yüksek $(0,785)$ ” gibi iş güvenliği algısına ilişkin maddeler bir araya gelmiştir. Boyutun açiklanan varyansı 49,332, özdeğeri 4,440 ve güvenilirliği 0,836 olarak belirlenmiştir.

Tablo 5: Değişkenler Arası İlişkiler Korelasyon Tablosu

\begin{tabular}{|l|c|c|l|l|}
\hline & İ̧̧ güvenliği & Dışsal Risk & İçsel Risk & Kadercilik \\
\hline iş güvenliği & 1 & & & \\
\hline Dışsal Risk & $0,035^{*}$ & 1 & & \\
\hline İçsel Risk & $0,305^{*}$ & 0,000 & 1 & \\
\hline Kadercilik & $0,323^{*}$ & $0,093^{*}$ & $0,204^{*}$ & 1 \\
\hline
\end{tabular}

${ }^{*} \mathrm{P}<0,01$

Yeraltı madencilerinin iş güvenliği algıları yaşanan kazalar sonucu oluşan dişsal risk algısı ile $(\mathrm{r}=0,035 \mathrm{p}<0,01)$, içsel risk algısı ile $(\mathrm{r}=0,305 \mathrm{p}<0,01)$, kadercilik algısı ile $(\mathrm{r}=0,323 \mathrm{p}<0,01)$ pozitif anlamlı bir ilişkiye sahiptir. Ayrıca yeraltı madencilerinin yaşanan kazalar sonucu oluşan dışsal risk algıları ile kadercilik algıları arasında $(r=0,093$ 
Tablo 6: Çoklu Regresyon Analizi Sonuçları

\begin{tabular}{|c|c|c|c|c|c|c|c|}
\hline \multirow{2}{*}{ Bağımsız Değişkenler } & \multicolumn{2}{|c|}{ Standardize Edilmemiş } & \multirow{2}{*}{$\begin{array}{c}\begin{array}{c}\text { Standardize } \\
\text { Edilmiş }\end{array} \\
\beta\end{array}$} & \multirow{2}{*}{$\mathrm{t}$} & \multirow{2}{*}{ Sig. } & \multirow{2}{*}{ VIF } & \multirow{2}{*}{ Sonuç } \\
\hline & $\beta$ & Hata & & & & & \\
\hline Sabit & 27,120 & 1,073 & & 25,281 & ,000 & & \\
\hline Dışsal Risk (H1) & 079 & ,289 & ,010 & ,274 & ,784 & 1,009 & Red \\
\hline İçsel Risk (H2) & 1,926 & 294 & 249 & 6,554 & ,000 & 1,044 & Kabul \\
\hline Kadercilik (H3) & ,535 & ,075 & 271 & 7,104 & ,000 & 1,053 & Kabul \\
\hline
\end{tabular}

$\mathrm{p}<0,01)$, içsel risk algısı ile kadercilik algıları arasında $(\mathrm{r}=0,204 \mathrm{p}<0,01)$ pozitif anlamlı bir ilişki bulunmuştur.

Çoklu regresyon analizi sonuçlarına göre yeraltı madencilerinin iş güvenliği algılarını yaşanan kazalar sonucu oluşan içsel risk algısı $(\beta: 0,249 \mathrm{p}<0,01)$ pozitif olarak, kadercilik boyutu $(\beta: 0,271 \mathrm{p}<0,01)$ pozitif olarak etkilemektedir. Çalışmanın $\mathrm{H} 1$ ve $\mathrm{H} 3$ hipotezleri kabul edilmiştir. Ancak yeraltı madencilerinin iş güvenliği algıları üzerinde dışsal risk algısının 0,05 anlamlılık düzeyinde istatistiksel olarak anlamlı bir etkisinin olmadığı belirlenmiştir.

\section{SONUÇ VE ÖNERİLER}

İş sağlığı ve güvenliği çalışanların fiziksel, sosyal ve psikolojik refahlarını en iyi seviyelerde tutmayı amaçlamaktadır. Sahip olduğu potansiyelinin ne kadarını çalıştığı örgüt için kullanacağına karar verme yetkisine sahip olan çalışan, temel ihtiyaçlarından olan sağlı ve güvenliğine verilen önemi anında değerlendirmekte ve ona göre işiyle olan bağlarını kuvvetlendirmektedir. Bu sebeple teknolojik gelişmeler, iş yapış şekillerindeki değişimler, iş sağlığı ve güvenliği uygulamalarının da sürekli güncellenmesini gerektirmektedir. İş sağlığı ve güvenliğinin temel bir amacı yaşanan değişimler çerçevesinde çalışanların refahının sürekliliğini temin etmektir. Çalışırken ortaya çıkabilecek kazaları minimize etmek ve ya mesleğin yapısına bağlı olarak ortaya çıkması muhtemel meslek hastalıklarıyla mücadele etmek iş sağlığı ve güvenliğinin önemini ve sürekli kendini yenilemesi gereğini göstermektedir.

Örgütlerin iş sağlı̆̆ı ve güvenliğine verdikleri önem sosyal sorumluluk anlamında toplumun örgüte bakışını da etkilemektedir. Toplumsal çevre, örgütü, kültürel anlamda çevreleyen ve örgütün faaliyetleri üzerinde yaptırıcı etkileri olan bir sistemdir. Riskli ve tehlikeli endüstrilerde iş sağlığ1 ve güvenliği uygulamalarına verilen önem örgütün imajını belirleyici güçlerden olmaktadır. Gerek insan kaynağı gerek müşteri olarak toplumun örgüte verdiği destek yoğun rekabet ortamında örgütler için çok kıymetli olmaktadır. Örgütün iş sağlığı ve güvenliği uygulamalarına verdiği önem ve aktardığı yatırımlarla bu destek güçlendirilebilecektir.
Riskli ve tehlikeli ağır endüstri sektöründe çalışanların iş sağlığı ve güvenliği konularına verilen önem aynı zamanda örgüt kültürünü şekillendiren yapı taşlarındandır. Yer altı madenciliğinde çalışanların kaza ve yaralanmalar sonucu oluşan risk algılarının yoğunluğu kaderci bir bakış açısıyla hafifletilebilmektedir. Burada dikkat edilecek nokta kaderci yaklaşımın, iş sağlığı ve güvenliği uygulamalarının hafife alınmasına yol açacak boyuta getirilmemesidir.

$\mathrm{Bu}$ çalışmada risk algısı ve kaderci yaklaşımın iş sağlığı ve güvenliği üzerindeki nedensel ilişkileri incelenmiştir. Yaşanan kaza ve yaralanmalar sonucu oluşan risk algısı yer altı madenciliğinin çalışma ortamından kaynaklanarak ikiye ayrılmıştır. Yangın, gaz ve toz patlaması, zehirlenme, su basması, elektrikten kaynaklanan kazalar şeklinde dış etkenlerin yarattığı bir risk algısı oluşmuştur. Diğer bir gruplanma da kişinin kendisinden kaynaklanan kayma, dengesini kaybedip düşme, el aletlerinin kullanımından dolayı yaralanma, elle veya mekanik taşımadan kaynaklı yaralanma gibi kazalar belirmiştir. Dış etkenlerden kaynaklanan iş kazalarının iş güvenliği algısı üzerinde anlamlı bir etkisinin olmadığı ancak kişinin kendinden kaynaklı kazaların iş güvenliği ve kadercilik algılarını etkilediği görülmüştür.

\section{KAYNAKÇA}

Ayan, Burak, Ekrem Çakmak, Esra Karaman ve Derya Koçak, 2013; Mahalli İdarelerde İş Sağlığı ve Güvenliği Risk Değerlendirmesi, Çalışma ve Sosyal Güvenlik Bakanlığı, Çalışma ve Sosyal Güvenlik Eğitim ve Araştırma Merkezi (ÇASGEM) Yayını.

Aytaç, Serpil, Ahmet Fahri Özok, Nurettin Yamankaradeniz, Gizem Akalp, Oğuzhan Çankaya, Ahmet Gökçe, Ulviye Tüfekçi, 2017; İSG Kültürü Oluşmasında Metal Sanayide Çalışan Kadınların Risk Algısı Üzerine Bir Araştırma, Mühendislik Bilimleri ve Tasarım Dergisi 5 (ÖS: Ergonomi2016), Özel Sayı: 22. Ulusal Ergonomi Kongresi e-ISSN: 1308-6693, ss. 59-67. 
Chapman, Judith Ann, 2007; Safe Workplaces: A Key Issue for Quality of Working Life, Employment Relations Record, Vol. 7, No. 1, pp. 25-35.

Demirbilek, T. (2005), İş Güvenliği Kültürü, Legal Yayıncllık, İstanbul.

Eastman, Crystal (1969); Work Accidents and The Law, Arno \& The New York Times, New York.

Esparza, Oscar A. (2005); "Factors Derived from Fatalism Scales and Their Relationship to Health-Related Variaibles, "Yayınlanmamış Yüksek Lisans Tezi, The University of Texas At Al Paso - Department of Psychology, UMI Number: 1430930.

Gruenspecht, Howard K. ve Lester B. Lave (1988); "The Economics of Health, Safety and Environmental Regulation," Handbook of Industrial Organization Volume II, Edt.: Richard Schmalensee ve Robert D. Willing, Elsevier Science Publishers, North Holland. s.1507-1550.

Gyekye, Seth Ayim (2003); "Causal Attributions of Ghanaian Industrial Workers for Accident Occurrence: Miners and Non-miners Perspective," Journal of Safety Research, Cilt 34, Sayı 5, s. 533-538.

Lingard, Helen, 2002; The Effect of First Aid Training on Australian Construction Workers' Occupational Health and Safety Knowledge and Motivation Avoid Work-Related Injury or Illness, Construction Management and Economics (2002) 20, 263-273

Neville, Haig (1998); "Workplace Accidents: They Cost More Than You Might Think," Industrial Management, Jan/Feb 1998; 40, 1, s. 7-9.

Özden, Ali Tolga, 2012; Türkiye'de Yaşanan İş Kazaları ve İșçi Ölümleri: Kader mi Yoksa Kadercilik mi?, Bülten, Mimarlar Odası Ankara Şubesi Yayını, No: 98, ss. 4251, Ankara.

Rundmo, Torbjorn ve Andrew R. Hale (2003); "Managers' Attitudes Towards Safety and Accident Prevention," Safety Science 41 (2003), s.557-574.

Tarhan, Şebnem, Ergin Kahraman, H.Hakan Erdem, Cemalettin Sığırcı, Fatih Bülent Taşkın, (2012); “Tam Mekanize Çayırhan Yeraltı Linyit İşletmesinde 20082011 Yılları Arasında Meydana Gelen İş Kazalarının Değerlendirilmesi," Türkiye 18. Kömür Kongresi Bildiriler Kitabı, 06-08 Haziran 2012, Zonguldak, s. 369382.
Uslu, M. (2002). Kazaların Oluş Sebepleri, Bıçaklar Kitabevi, Ankara.

Yavan, Öznur, 2013; Gizli Maliyetlerin Yapısal Eşitlik Modeli ile Analizi Üzerine Bir Araştırma, Yayınlanmamış Doktora Tezi, Bülent Ecevit Üniversitesi Sosyal Bilimler Enstitüsü, Zonguldak. 